\title{
Distribution Patterns and Multilevel Factors of the Innovation Activities of China's New Energy Vehicle Industry
}

\author{
Kaihuang Zhang ${ }^{1}$, Qinglan Qian ${ }^{1, *}$ and Zhixin Feng ${ }^{2}$ \\ 1 School of Geography and Remote Sensing, Guangzhou University, Guangzhou 510006, China; \\ 2111801047@e.gzhu.edu.cn \\ 2 School of Primary Care, Population Sciences and Medical Education, University of Southampton, \\ Southampton SO16 6YD, UK; z.feng@soton.ac.uk \\ * Correspondence: geo_qianql@gzhu.edu.cn
}

check for

updates

Citation: Zhang, K.; Qian, Q.; Feng, Z. Distribution Patterns and Multilevel Factors of the Innovation Activities of China's New Energy Vehicle Industry. ISPRS Int. J. Geo-Inf. 2021, 10, 385. https://doi.org/ $10.3390 /$ ijgi10060385

Academic Editors: Wolfgang Kainz, Giuseppe Borruso, Beniamino Murgante, Carmelo Maria Torre, Hartmut Asche and Ginevra Balletto

Received: 25 April 2021

Accepted: 2 June 2021

Published: 4 June 2021

Publisher's Note: MDPI stays neutra with regard to jurisdictional claims in published maps and institutional affiliations.

Copyright: (c) 2021 by the authors. Licensee MDPI, Basel, Switzerland. This article is an open access article distributed under the terms and conditions of the Creative Commons Attribution (CC BY) license (https:// creativecommons.org/licenses/by/ $4.0 /)$.

\begin{abstract}
To better understand the multilevel mechanism of innovation and reveal the distribution and geographical formation of China's NEV industry innovation, we collect patent data in China's NEV industry from SIPO and use ArcGIS and HLM to map and analyze its geoinformation from 2009 to 2014. The results show that innovation activities are agglomerated at different scales, but the distribution of individual innovation and collaborative innovation are not similar, especially Pearl River Delta, which shows a great shortage of collaborative innovation. The multilevel effects are complicated. Institutional environment, resources, the regional institutional environment, and infrastructure have positive effects at the local level. Institutional environment is the only positive factor at the regional level. In general, regional factors enhance the positive effects of local factors. However, multilevel mechanism of collaborative innovation is different from the individual innovation, as it is less depended on policies stimulation and local knowledge institutions play a more important role in it. Furthermore, we put forward multilevel policies suggestions that central government should pay more attention on NEV products regulations, institutional environment should be improved at regional and local government should develop knowledge facilities in post-subsidy era. Our study highlights that locals that have advantages would benefit more from multilevel systems.
\end{abstract}

Keywords: collaborative innovation; distribution patterns; innovation activities; multilevel mechanism; new energy vehicle; China

\section{Introduction}

Agglomeration is notable in the distribution patterns of innovation activities and their geographical environment contexts are multilevel [1]. First, as the Global Innovation Index 2019 shows, innovation distributions are highly agglomerated. According to this report, from a global point of view, the top 10 scientific innovation clusters occupied $35.27 \%$ in the global Patent Cooperation Treaty (PCT) application, of which, Tokyo-Yokohama, ShenzhenHongkong, and Seoul occupied 10.9\%, 5.54\%, and 3.95\% globally, and Beijing, San Jose-San Francisco (CA), Osaka-Kobe-Kyoto, Boston-Cambridge (MA), New York City (NY), Paris, and San Diego (CA) are the other seven top innovation clusters. From a national point of view, some regions are always clusters in a country. In the United States, the Great Lakes, Bay areas, and South California are the predominant clusters in research and innovation [2]. In China, the Yearbook of 2019 Statistics shows that Guangdong, Jiangsu, and Zhejiang together occupied 51\% in the national PCT application. From the view of a much smaller scale, many empirical studies provide pieces of evidence that innovation clusters feature prominently in special regions [3]. Second, the geographical environment context of innovation activities has multilevel characteristics. Although organizational relations, social relations, and cognitive direction can help innovation across local communities [4], innovators are still sensitive to geographical distance [5]. Knowledge spillover is usually limited in certain geographical spaces. However, this does not mean that the innovation 
environment on a larger scale is useless. Conversely, the space boundary of innovation has become more and more blurry, and it is difficult to understand many innovation activities in a single scale [6]. Meanwhile, companies are sensitive with geographical distance because of the space dependency of knowledge spillover [7]. With the boundary becoming blurry and companies are localized, innovators are embedded into the local innovation system, and local innovation systems are embedded into the regional and national innovation system, thus multilevel relationships have been built [8].

Although multilevel innovation distribution and the multilevel mechanism has been of concern $[9,10]$, the empirical studies of multilevel mechanism of innovation distribution and its cross-level effect are still limited. For this reason, we put forward three theoretical questions, "what are the multilevel geographical results caused by central government intervention?", "how do regional and local innovation environment impact innovation activities distribution?", and "how the cross-level effect in multilevel innovation environments works?". In fact, from a view of innovation output, the number of innovators could be one or more. Therefore, to discover the multilevel mechanism of innovation, we further divided the innovation activities into individual innovation and innovation networks.

To answer the above questions, we choose the new energy vehicle (NEV) industry as the research objective. Since it is an innovative emerging sector that is with traditional automotive technology and new energy automotive technology [11], industrial knowledge shows tacit and explicit. Thus, its innovation activities would be multilevel. As NEV industry development is highly influenced by policies, most studies are focused on how policies influence innovation, and our knowledge of geographical patterns and multilevel mechanism of the NEV industry innovation activities is still very limited. For these reasons, there is a research gap need to fill. We choose China's NEV industry as a study case, because it is significantly influenced by policies and China is also the biggest NEV consumption country globally [12]. Therefore, our study is suitable for international and local interests both.

In general, this study aims to utilize GIS to visualize the distribution of innovation activities, individual innovation, and collaborative innovation in China's NEV industry, and also tries to build a series of related variables to analyze its multilevel mechanism with HLM. According to this, the contributions of this work are as followed:

- $\quad$ Reviewing related works and organizing them into a multilevel dimension.

- Mapping different distributions of innovation activities and collaborative innovation, summarizing and comparing the multilevel mechanism of innovation activities, and collaborative innovation.

- Providing a visualized distribution map of NEV industry innovation to governments, and delivering policy suggestions according to the knowledge of China's NEV industry innovation mechanism.

The study's structure is as follows: in the next section, we review previous studies, the multilevel geographical mechanism of innovation, and the industrial context of China's NEV industry; based on this background, we introduce our data sources, variables selection, and methodology in Section 3; in Section 4, the results of the distribution and multilevel analysis of innovation activities are shown; in Section 5, we discuss the general multilevel mechanism of innovation activities and give some governance advices; finally, we present the conclusions of the study in Section 6.

\section{Literature Review}

\subsection{Innovation Agglomeration Mechanism}

Generally, most of innovation activities are agglomerated in metropolitan areas, because there is a sharing, matching, and knowledge spillover mechanism. For example, in United States, from 2011 to 2015, 36.5 percent of new patents are clustered in California, New York, and Texas [1]. To discover the innovation agglomeration mechanism, sharing, matching, and knowledge spillover are known as a convincible theory [13]. 1. Clusters have a scale effect and when the scale is strong enough, the members of the cluster will 
benefit [14]. With strong supply chains, the costs of innovation can be decreased, the risks of innovators could be lower [15]. 2. Agglomeration can also increase labor quality for innovative companies. On the one hand, in metropolitans, firms can find skilled laborers at a lower price [16], due to numerous workers with high mobility in the region. On the other hand, higher educated labors would increase employee's seeking opportunities capability and achieve new knowledge [17], which would improve their skill and finally benefit firms. 3. Knowledge spillover is a result of firms and human capital agglomeration [18]. When the staff communicate with each other, the transmission of tacit knowledge will occur anytime and anywhere [19]. Meanwhile, geographical proximity decreases the cost of intellectual property transactions, as there is a trust built among the innovators and strong social connection could decrease transactions risks [20].

\subsection{Multilevel Innovation Systems}

Innovation activities are organized in a multilevel framework, and what we should care about are different at the multilevel: 1 . Actors level: with a different level of absorptive capacity, the efficiency of knowledge flows would be different and finally influence innovation output [21]. 2. Innovation networks between the actors level: the status of the actor in the network, the linkages' types, and intensity of links [22]. Those relationships would break the border of geographical space and innovation activities would face a power of centrifugal force, at a degree [23]. 3. Local and regional level: the agglomeration effect is empathized and innovators are embedded into space and innovation activities would also face a power of centripetal force, because of the existence of tacit knowledge [24]. 4. National level: the central government utilize policies tools at the background of society and environment, and put influences on the industrial innovation to achieve development goals [25]. 5. Global level: this lens is beyond the nation boundary and it is a scale that innovators find and create knowledge [26]. In our research, we focus on the "nation-regionlocal" three level. With the central government's long-term support, China's NEV industry is developing and shows an endogenous characteristic. That means, national, regional, and local innovation systems play a considerable role.

\subsubsection{National Innovation System}

Industrial policy is the most important factor at the national level. In the theories of the national innovation system (NIS), the institutional context is considered as the key factor. By implementing policies, the central government could influence the direction of companies' and industrial development, and find its industrial trajectory to face the competition in the international market [27]. A study in electric vehicle innovation shows that the government's subsidy policy, especially the consumer subsidy, could popularize new technology in the market and make a breakthrough innovation [28]. However, research about the NEV innovation in Japan shows the limited effect of policy [29]. This argument also can get support from another study, in which academicians find the policies that are more than ten years old are not effective with South Korea's economic development [30]. In fact, although the national policy could put impact on innovation in the long-term, the NIS concept means all innovators are in a homogeneity geographical context of the control of the central government [31]. Undoubtedly, the innovation environment would be different among countries and areas, and such an NIS hypothesis is much more suitable in a small country. Therefore, for China, it is critically important to focus the innovation environment in the region and local scale.

\subsubsection{Regional Innovation System}

The regional innovation system (RIS) can be used at the regional and local level. RIS is used to analyze innovation distribution, and it can be divided into the innovation environment, innovation resources, and innovation facilities. In "2.1 Agglomeration in the distribution of innovation activities", we pointed out that, sharing, matching, and knowledge spillover is the main mechanism of innovation agglomeration. In other words, 
a cluster at the local level could make knowledge spillover and innovation occurrence become possible [32]. The dependency of companies to the local level not only exist on financial capital, human capital, infrastructure, and a supply service, but also the environment, which could benefit from innovation [33]. With the influence of economic factors and institutional thickness, innovators are embedded into the local level and build space dependency. That means, innovation is under the influence of a centripetal force in space [34], and locals are nested in regions with a multilevel relationship. Therefore, RIS shows a good explanation in this process.

Specifically, these forces are from the innovation environment, innovation resources, and innovation facilities. In addition, as the region's boundary is not clear, the RIS is usually applied at the local level.

Innovation environment includes the institutional environment, industrial policies, and industrial base, they play a foundational role in local innovation. After the reform and opening, China took on a gradual economic transition strategy. With this, there are three changes in the institutional environment, including marketization, decentralization, and globalization, and there is also a territorial differentiation in the institutional environment [35]. After reforming, the multilevel government had obtained more power, and they have great motivation to develop the local economy, so they tried to encourage marketization and globalization [36]. Some evidence shows that with the market mechanism being constructed, free mobility of capital and labor becomes true, and this boosts the enterprisers' spirit, thus the flow of knowledge was increased too [37]. As a consequence, the faithful and competitive market accelerated innovation. In the meantime, globalization strengthened the links between the local and external world, and new knowledge comes into contact with locals and combines with the local knowledge by investment and trade, and thus, innovation grows [38,39]. With more governance and financial permissions, regional and local governments began to publish territorial industrial policies. Since there is a GDP competition among governors, local governments usually publish favorable policies to attract actors and encourage innovation, although those regions may not have advantages in innovation. A study result about Shanghai stands for this argument [40]. Researchers find that governments' R\&D input could increase entities' innovation output, but there is a mismatching feature in it. In addition, as "Modularization" becomes the significant feature in production, the duties of suppliers in different sections also become clear [41]. With this background, the agglomeration of suppliers could respond to innovators demand rapidly, and innovators in every section could be more effective and cost less, this would finally increase local innovation. The giants in the cluster could also impact local innovation capacity by their resources and knowledge of themselves.

Innovation resources includes finance capital, R\&D, and human capital and they play a role in local innovation development. The innovation of companies could not live without the support of finance capital. In fact, to innovative companies, those intangible assets (like patents) make up the major proportion in total assets. Therefore, for start-ups it is hard to obtain loans from traditional banks and those highly specific small firms are highly dependent on venture capital and investment funding. For that capital, it is much more likely for them to get overperformance at the local level, because they can get benefits from knowledge spillover at a closer distance [42]. Universities are important actors in innovation, with sustainable R\&D input, their scientific equipment could be improved. Thus, undoubtedly, this would make researchers create new knowledge and new technology more effectively [43]. Additionally, as a consequence, labor of high quality would be provided by universities to locals and regions [44], and highly skilled labor are also the key factors among territories [45]. To innovators in regions, it is quite important because abundant engineers would be the great treasure of the region, and labor cost would be lower too [46]. Although labor is flowing, the knowledge infrastructures could connect labor and locals tightly with social networks and space dependency.

Innovation facilities include foundational infrastructure, information infrastructure, and knowledge infrastructure and they make innovation become possible. Infrastructure 
plays an important role in innovation activities, as it provides support to innovators with an openness background [47]. Information facilities also provide technological support to rapid communication and data transmission among innovators, this determined the efficiency, depth, and width of innovation directly [48]. The intelligence resources could provide human capital to the region, on the one hand, and transmit knowledge among connections of actors, on the other hand.

\subsection{Policies and Progress in China's NEV Industry}

China is an important research subject in relation to the NEV industry research. "If the Chinese get some good ideas, they will put it into the market and carry out tests [49]". From a long-term view, China's NEV industry had been dependent on policy support, and it had rapidly developed in the last 20 years [50], and a set of related companies, universities, and suppliers had been built [51]. Therefore, the studies about China's NEV industry innovation are mainly about the macro impact of policies. With attracting financial subsidy, on the one hand, firms are encouraged to innovate, but policy arbitrage comes with it [52]. On the other hand, stimulated by subsidy, roads rights, and application in a public area, the NEV consumption would increase, so the manufacturers gain currency to start a new innovation [53].

Totally, influenced by industry policies, development stages in China's NEV policies can be divided into the "industry plan - R\&D investment - financial subsidies - regulating and gradually exiting subsidies". The industry plan started from 1995 to 2000. In 1995, the NEV industry was clearly pointed out as an important national technological project in the 9th Five-Year Plan. In 1999, thirteen departments published "A number of comments on the implementation of air purification projects to clean vehicles" [50]. The industry is still at a planning stage without substantial progress; innovation activities are very limited. R\&D investment is from 2001 to 2008. During this period, China began to create a foundational research project ("National high-tech R\&D plan for electric vehicles" was established in the 10th Five-Year Plan), and the number of the patents was increasing gradually. Financial subsidies are from 2009 to 2014. In 2009, the National Development and Innovation Committee (NRDC) published the "ten cities and a thousand cars" project, the "Plan for the adjustment and revitalization of the automobile industry," purchasing subsidies, and the "NEV production enterprises and product access management rules". These policies include pilot programs, infrastructure plans, preferential taxes, price subsidies, and R\&D investment. These measures made the market active and played an important role in sales improvements in 2012. Therefore, 2009 is regarded as an important year in China's NEV progress [54]. Since then, China has enacted a lot of favorable policies from purchasing tax, road rights, and subsidies to infrastructure, regulating, and gradually exiting subsidies began in 2015. Governments published regulations to intensify product supervision, regulate industrial standards, build a sustainable market mechanism, promote industry targets, and crackdown on disobedient firms.

In conclusion, on the one hand, from a theoretical view, the knowledge about the "multilevel mechanism of innovation activities" should be enriched. As there is a sharing, matching, and knowledge spillover mechanism, innovation actors and innovation activities would be clustered on a different scale. Although different level innovation systems are being focused on by researchers, the knowledge about how multilevel innovation systems together affect innovation activities is still unclear. On the other hand, from a view of industrial study, the distribution patterns and mechanism in China's NEV innovation should be paid more attention. In the near future, the financial subsidy in China's NEV industry would be cancelled. To better respond to a non-subsidy era and implement efficient policies, it is important for researchers and governors to understand the relationships between the multilevel innovation system and innovation in China's NEV industry. We thus collected China's NEV patent data from SIPO and used the GIS to visualize its superficial geoinformation. Furthermore, we utilized HLM to analyze the 
multilevel geographical mechanism of the spatiotemporal distribution changes in China's NEV industry innovation, so the underlying geoinformation could be discovered.

\section{Data and Methods}

\subsection{Data}

The data in our research are from the Chinese Patent Citation Database (CNPCD) of China's State Intellectual Property Office (SIPO). As patents in China will take 18 months and more time from application to approval, we collected patent data of NEV until 2017. A study shows evidence that there is a time lag from innovation input to innovation output [55]. Research on innovation in the NEV industry also points out that a 2009 policy affected innovation output after three years [56]. We decided to analyze NEV industry innovation from 2009 to 2014. On the one hand, the NEV industry was in the financial subsidies period from 2009 to 2014. During this period, the number of patents granted increased rapidly. Analyzing this period can help us deepen our knowledge about the effect of national subsidies. On the other hand, concerning the accuracy of the data, it would be much more complete before 2017, and 2017 corresponds to 2014 in relation to the time lag. Considering time lags can help us map innovation accurately. In this period, there are 13,400 patents in China's NEV industry. Due to the social and economic environment differences among cities, researchers chose 13 metropolitan areas that were set by the state council as regions in our study. There are 153 cities in these 13 metropolitan areas including the Beijing-Tianjin-Hebei Region (BTH, with 13 cities), Yangtze Delta River Region (YRD, with 26 cities), Pearl Delta River Region (PRD, with 9 cities), Lanzhou-Xining Region (with 9 cities), Hulunbeir-Baotou-Erdos-Yulin Region (with 4 cities), Guanzhong Plain Region (with 11 cities), Beibu Bay Region (with 11 cities), Central Plains Region (CPR, with 9 cities), Chengdu-Chongqing Region (CCCR, with 15 cities), Harbin-Changchun Region (with 11 cities), Middle Yangtze River Region (with 31 cities), Southeastern Fujian Region (with 6 cities), and Shandong Peninsula Region (with 8 cities). In these regions, the geographical distances between cities are relatively limited, the innovation connections between cities are relatively close, and these areas can be seen as a regional innovation environment or a local innovation environment. There are 12,367 patents in the above areas. We standardized these data by entropy method before we build a hierarchical linear model (HLM).

\section{Control variables:}

National industrial policies and time are the two factors that should be controlled, because the NEV industry is greatly influenced by China's central government from 2009 to 2014 , the time we analyzed in this paper.

As for national industrial policies, it should be divided into three parts include the supply side, demand side, and public environment in the NEV industry [57]. Therefore, we should consider the governance tools differently. We assigned 2 to those policies that have substantial preferences (such as subsidies, loans, rewards, and road rights), assigned 1 to those policies that have no substantial preferences, and assigned 0 when there are no policies.

The time (from 2009 to 2014) is treated as a controlled variable in this study to discover the change in this period.

\section{Independent variables:}

The factors at the regional and local level are the independent variables in our study. It includes environment, resources, and facilities.

As for the environment, the institutional environment, industrial base, and industrial policy are the three parts in this section. 1. The institutional environment is the regional and local milieu, so it is related to the regional and local comprehensive background. As some researchers have mentioned, decentralization, marketization, and globalization are the three major changes in China's regional and local governance [58], so we chose fixed assets investment, wholesale and retail sales revenue, and foreign direct investment as indicators. 2. The industrial base is quite important for NEV innovation, because traditional 
manufacturers are also the innovators in the emerging sector. To show the industrial base, we chose the listed auto companies that are defined under the industry classification of the China Securities Regulatory Commission as the variables. 3. The local or regional governments in China are competitive in economic developments, so the regional and local industrial policies are heterogenous. We collected policies data from official websites and valued them as we did at the national level.

As for the resources, we focused on the R\&D investment, financial investment, and human resources investment. 1. To better represent the R\&D in NEV research, we used research projects that are funded by the National Science Foundation of China as an indicator, because they show the high technology level and they are the most important project in China. 2. The financing investment should be focused on the NEV industry, so we collected related data from PEDATA. This database shows the venture capital (VC) and private equity (PE) financing activities in the NEV industry. 3 . The human resources investment is really critical in innovation. To analyze the professional researchers in NEV, we collected data from the Web of Science to find those universities and research institutions that have published articles in NEV knowledge innovation.

As for the facilities, we paid attention on the general infrastructure and telecommunication infrastructure context of NEV innovation. Additionally, we measured the infrastructure supply ability by water resources, energy resources, road infrastructure, and environmental infrastructure, and measure telecommunication infrastructure by the total telecommunication business volume. These data are from the China City Statistic Yearbook.

What we should point out is that the region in our study is the urban agglomeration, and they usually cover many cities in two or more provinces. Thus, the provincial and municipal policies are summed at the local level. Table 1 shows the selection of the variable indicators.

Table 1. The indicators of innovation activities and innovation environments.

\begin{tabular}{ccc}
\hline & Classification & Variables \\
\hline Dependent Variables & Innovation Output & Innovation Activities (IA) \\
Individual Innovation (II) \\
Control Variables & & Collaborative Innovation (CI) \\
& & National Industrial Policies (P) \\
& & Time (T) \\
& & Institutional Environment (InE) \\
& Environment & Marketization \\
Independent Variables & Decentralization \\
& & Globalization \\
& & Industrial Base (InB) \\
& Industrial Policy (LP) \\
& Resources & Financial Investment (Fin) \\
& Human Resources (HR) \\
& Infrastructure (Infra) \\
& Water resources
\end{tabular}

\subsection{Methods}

In this study, we used the entropy and hierarchical linear model (HLM) to analyze the multilevel factors of China's NEV industry innovation distribution. Firstly, because entropy can be used to weight the indicator objectively and make the variables be standardized, we used the entropy to weight indicators in variables including the institutional environment (InE) and infrastructure (Infra). Secondly, the HLM was used to analyze the multilevel factors effect, as it can measure how different level factors influence local innovation and 
how regional level factors influence local factors so that makes the distribution different. By using this method, a multilevel mechanism could be showed more clearly.

\subsubsection{Entropy Method}

The formula is as follows:

1. Standardization

Positive indicators:

$$
X_{i j}^{\prime}=\frac{X_{i j}-\operatorname{MIN}\left[X_{j}\right]}{M A X\left[X_{j}\right]-M I N\left[X_{j}\right]}
$$

Negative indicators:

$$
X_{i j}^{\prime}=\frac{M A X\left[X_{j}\right]-X_{i j}}{M A X\left[X_{j}\right]-M I N\left[X_{j}\right]}
$$

$X_{i j}$ refers to the indicator $\mathrm{j}$ in $\mathrm{i}$ city or province. $M A X\left[X_{j}\right]$ refers to the maximum of indicator $\mathrm{j}, M I N\left[X_{j}\right]$ refers to the minimum of indicator $\mathrm{j}$, and $X_{i j}^{\prime}$ refers to the standardized indicator.

2. Information entropy and the weights

Information entropy:

$$
E_{j}=-K \sum_{i=1}^{n}\left[p_{i j} \ln p_{i j}\right]
$$

$\mathrm{K}=\ln [n]^{-1}, p_{i j}=\frac{X_{i j}}{\sum_{1}^{n} X_{i j}}$, assuming $p_{i j}=0, E_{j}=0$, and $n$ is the total number of the cities and provinces.

Weights:

$$
W_{j}=\frac{D_{j}}{\sum_{1}^{k} D_{j}}
$$

$D_{j}=1-E_{j}, D_{j}$ refers to the difference among indicators, the higher the difference is, the greater the $D_{j}$ is, and the bigger the indicators' weights are. When $D_{j}=0$, the data of indicators are totally not different, and their difference is minimal.

\subsubsection{Hierarchical Linear Model}

We built a three-level model in this study to analyze innovation activities by using an HLM. The first level was used to analyze the effect of control variables (national policies and the duration) on the innovation activities' distribution. The coefficient we get will be fixed in level two and level three. The second level was used to analyze the effect of the municipal innovation environment on the innovation activities' distribution, and the third level was used to analyze the effect of the regional innovation environment on the innovation activities' distribution.

First level:

$$
Y_{i j}=\beta_{0}+\beta_{1} T+\beta_{2} P+\varepsilon_{i j}
$$

Second level:

$$
\beta_{0}=\gamma_{00}+\gamma_{0 k} X_{i j k}+r_{0 i}
$$

Third level:

$$
\begin{aligned}
& \gamma_{00}=\varphi_{000}+\varphi_{00 n} R_{j n}+\tau_{00} \\
& \gamma_{0 k}=\varphi_{0 k 0}+\varphi_{01 n} R_{j n}+\tau_{01}
\end{aligned}
$$

In this analytical model, $T$ is the time and $P$ is the national policy. Subscript $I$ and $j$ are the city and region, respectively. The variable $Y_{i j}$ is the innovation activity in city $i$ of region $j . \beta_{1}$ and $\beta_{2}$ are the fixed effects of the time and policies. $\beta_{0}$ is the effect of the municipal innovation environment and the regional innovation environment. $X_{i j k}$ is the factor $k$ of city $i$, which is in region $j . \gamma_{0 k}$ is the slope of factor $k$ in the municipal innovation 
environment. $\gamma_{00}$ is the intercept of factors at the municipal level. It is a surplus in a municipal innovation environment, and it is also the strength of influence in a regional innovation environment. $R_{j n}$ is the factor $n$ in the regional innovation environment. $\varphi_{00 n}$ is the slope of factor $n$ in the regional innovation environment. $\varphi_{01 n}$ is the effect of factor $n$ in the regional innovation environment in relation to factor $k$ in the municipal innovation environment. $\varphi_{000}$ and $\varphi_{0 k 0}$ are the intercepts of the regional innovation environment. $\varepsilon_{i j}$, $r_{0 i}, \tau_{00}$, and $\tau_{01}$ are residual errors in the model.

\section{Results}

By using entropy, we analyzed the variables of the institutional environment and the infrastructure from 2009 to 2014. Table 2 shows the weight of the indicators of the variables. The results show that marketization and globalization dominated the institutional environment at the municipal and regional levels. The level of marketization was 0.485 and 0.474 at the municipal level and regional level, respectively. The level of globalization was 0.372 and 0.327 at the municipal level and regional level, respectively. The weight of indicators in relation to infrastructure was more balanced. The level of road infrastructure at the municipal level was 0.264 . It only became 0.191 at the regional level. The level of energy resources was more proportional at the regional level; it was 0.197 at the municipal level, but 0.271 at the regional level.

Table 2. The result of the entropy analysis of institutional environments and infrastructure.

\begin{tabular}{cccccc}
\hline & & Municipal & \multicolumn{3}{c}{ Regional } \\
\hline Variables & Indicators & Redundancy & Weight & Redundancy & Weight \\
\hline \multirow{2}{*}{ Institutional } & Marketization & 0.210 & 0.485 & 0.172 & 0.474 \\
Environment & Decentralization & 0.062 & 0.143 & 0.073 & 0.199 \\
& Globalization & 0.161 & 0.372 & 0.119 & 0.327 \\
& Water Resources & 0.116 & 0.307 & 0.130 & 0.293 \\
Infrastructure & Road Infrastructure & 0.100 & 0.264 & 0.084 & 0.191 \\
& Energy Resources & 0.074 & 0.197 & 0.120 & 0.271 \\
\hline
\end{tabular}

To avoid the results at the municipal level from being significantly changed after introducing the regional model, we built the best model by choosing the variables that were significant at the municipal model, and then we introduced regional variables into the model. The regional variables that we introduced were those significant factors that directly affected innovation activities. Table 3 shows the descriptions of the variables.

Table 3. Description of the variables.

\begin{tabular}{|c|c|c|c|c|c|c|c|c|c|}
\hline $\begin{array}{c}\text { Dependent } \\
\text { Variables }\end{array}$ & AVG & $\begin{array}{l}\text { Standard } \\
\text { Deviation }\end{array}$ & Min & Max & $\begin{array}{c}\text { Control } \\
\text { Variables }\end{array}$ & AVG & $\begin{array}{l}\text { Standard } \\
\text { Deviation }\end{array}$ & Min & Max \\
\hline IA & 3.12 & 9 & 0 & 34.15 & $\mathrm{~T}$ & 2010.07 & 1.73 & 2009 & 2014 \\
\hline II & 4.73 & 13.64 & 0 & 51.7 & $\mathrm{P}$ & 13.93 & 8.84 & 8 & 29 \\
\hline CI & 3.24 & 10.69 & 0 & 40.33 & - & - & - & - & - \\
\hline $\begin{array}{l}\text { Municipal } \\
\text { Level }\end{array}$ & AVG & $\begin{array}{l}\text { Standard } \\
\text { Deviation }\end{array}$ & Min & $\operatorname{Max}$ & $\begin{array}{l}\text { Regional } \\
\text { Level }\end{array}$ & AVG & $\begin{array}{l}\text { Standard } \\
\text { Deviation }\end{array}$ & Min & Max \\
\hline $\operatorname{In} B$ & 0.06 & 0.11 & 0 & 0.4 & InB & 0.12 & 0.06 & 0.08 & 0.16 \\
\hline $\mathrm{InE}$ & 0.05 & 0.10 & 0 & 0.91 & $\operatorname{InE}$ & 0.18 & 0.21 & 0.00 & 0.99 \\
\hline R\&D & 0.02 & 0.05 & 0 & 0.17 & R\&D & 0.07 & 0.09 & 0 & 0.13 \\
\hline Fin & 0.03 & 0.06 & 0 & 0.21 & Fin & 0.12 & 0.16 & 0.01 & 0.24 \\
\hline $\mathrm{HR}$ & 0.05 & 0.15 & 0 & 0.55 & $\mathrm{HR}$ & 0.24 & 0.34 & 0 & 0.48 \\
\hline Infra & 0.09 & 0.14 & 0.01 & 0.46 & Infra & 0.22 & 0.21 & 0.07 & 0.37 \\
\hline Tele & 0.1 & 0.22 & 0.01 & 0.81 & Tele & 0.38 & 0.42 & 0.08 & 0.67 \\
\hline $\mathrm{LP}$ & 0.06 & 0.15 & 0 & 1.00 & - & - & - & - & - \\
\hline
\end{tabular}


Except for innovation activities, to show the difference between individual innovation and collaborative innovation, we analyzed innovation activities, individual innovation, and collaborative innovation separately.

\subsection{Distribution Patterns}

We used the ArcGIS to map innovation activities from 2009 to 2014, individual innovation, and the collaborative innovation of China's NEV industry. The results are shown in Figure 1. We found the following.

1. Innovation activities showed multilevel agglomeration features. Innovation were not only clustered in some metropolitan areas, but also agglomerated on a bigger scale. The data shows that, in China's NEV industry, Beijing, Shenzhen, and Shanghai represented $27 \%$ of innovation activities nationwide. Their innovation activity levels were 1511, 731, and 644, respectively. At the regional level, BTH, YRD, and PRD represented 1973, 3873, and 1472 of innovation activities, respectively. A total of $68.6 \%$ of the innovation in China's NEV industry was located in these regions.

2. The distribution patterns of individual innovation and collaborative innovation were not the same. Regions with a great amount of individual innovation may not maintain their collaboration advantages. The data showed that in China's NEV industry, BTH, YRD, and PRD created a lot of individual innovation. They had $16.2 \%, 36.6 \%$, and $14.1 \%$ of the individual innovation in China, respectively. However, regarding collaborative invention, PRD showed an unusually weak situation. Its collaborative inventions represented only $4.2 \%$ of collaborative inventions in China. However, BTH and YRD represented more than $31 \%$ of collaborative inventions in China. On the other hand, although the CPR and the CCCR only represented a small proportion of individual innovation (CPR represented $2.5 \%$ and CCR represented $5.8 \%$ ), these regions represented a higher proportion of collaborative innovation (CPR represented $5.0 \%$ and CCR represented $11.0 \%$ )
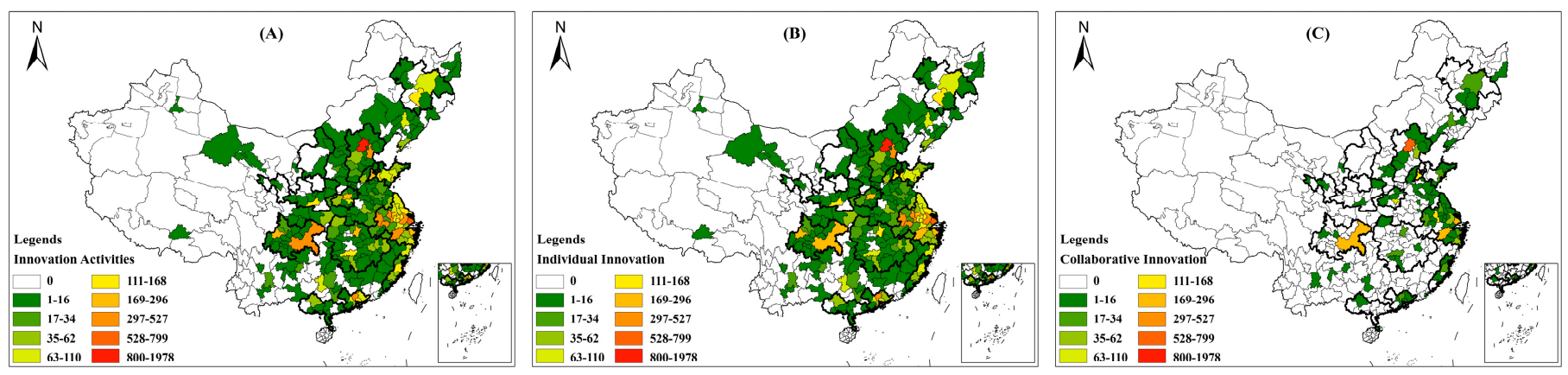

Figure 1. The distribution of China's NEV innovation: (A) is the distribution of innovation activities, (B) is the distribution of individual innovation, and $(\mathbf{C})$ is the distribution of collaborative innovation.

\subsection{Multilevel Analysis Results}

\subsubsection{Innovation Activities}

Table 4 is the multilevel analysis results of innovation activities in China's NEV industry. At the municipal level, human resources was the key factor of innovation activities distribution in China's NEV industry, its coefficient was 27.24. This also means whether locals own knowledge creation institutions would be quite critical. The institution environment played an important role too, its coefficient was 25.79 and it made China's NEV industry innovation output regionally different. Besides, the R\&D input and finance environment created a significant positive influence, the coefficient of them was 14.24 and 15.66 separately. It also means that the places with more R\&D would be with more competitive. Although municipal and provincial policies were with positive impacts, their effects were still weak compared with the local environment; the coefficient was only 5.19. 
Table 4. The multilevel analysis results of innovation activities.

\begin{tabular}{cccccccccc}
\hline & Municipal & InB & InE & R\&D & Fin & HR & Infra & Tele & LP \\
\hline Regional & Coefficient & 1.69 & $25.79^{* * *}$ & $14.24^{* * *}$ & $15.66^{* * *}$ & $27.24^{* * *}$ & 4.33 & -2.57 & $5.19^{* * *}$ \\
\hline InB & $-6.14^{*}$ & - & $10.00^{*}$ & $11.77^{*}$ & 10.72 & 2.36 & - & - \\
InE & $24.21^{* * *}$ & - & $29.70^{* * *}$ & $32.13^{* * *}$ & $55.39^{* * *}$ & $39.18^{* * *}$ & - & - & $4.23^{*}$ \\
R\&D & $-3.05^{*}$ & - & $14.23^{* * *}$ & $27.66^{* * *}$ & $45.66^{* * *}$ & $26.58^{* * *}$ & - & - & -0.12 \\
Fin & $-1.96^{*}$ & - & -5.27 & $15.17^{* * *}$ & $21.05^{* *}$ & $20.12^{* * *}$ & - & - & -0.71 \\
HR & $-6.80^{* *}$ & - & 9.74 & $32.73^{* * *}$ & $42.98^{* * *}$ & $34.42^{* * *}$ & - & - & -2.84 \\
Infra & -0.42 & - & $42.15^{* * *}$ & $23.94^{* * *}$ & -8.94 & $24.55^{*}$ & - & - & $10.07^{* * *}$ \\
Tele & $-4.76^{* *}$ & - & $27.04^{* * *}$ & $32.17^{* * *}$ & 3.77 & $22.02^{*}$ & - & - & $8.10^{* *}$ \\
\hline National & - & - & - & - & - & - & - & - \\
\hline P & -1.64 & - & - & - & - & - & - & - \\
T & 0.08 & - & - & - & - & - & - & - \\
\hline
\end{tabular}

Note: ${ }^{*}$ means $p \leq 0.05,{ }^{* *}$ means $p \leq 0.01$, and ${ }^{* * *}$ means $p \leq 0.001$.

At the regional level, the institutional environment was the most critical factor at the regional level, its coefficient was 24.21 and this means that those places with a good institutional environment were more likely to create NEV innovation. When we observe the other factors at the regional level, the human resources, industrial base, telecommunication business, finance capital, and R\&D input were all weak and negative with local innovation, their coefficients were $-6.8,-6.14,-4.76,-1.96$, and -3.05 . This means, even if regions get advantages in the above aspects, they do not have a great possibility of creating NEV technology. In another words, local innovation cannot be of benefit generally from the regions that are with advantages in the above aspects. At the same time, compared with the region, to those factors, the local level shows more significant advantages.

In the cross-level relationship from region to local, every factor strengthened the positive effects of factors at the municipal level. Specifically, the regional industrial base strengthened the impact of local institutional environment and R\&D input, the coefficients were 10.00 and 11.77 though the significance of this process was weak. The regional institutional environment and R\&D input significantly and strongly strengthened the positive effects of the local institutional environment, R\&D input, finance capital, and research institutions, and the coefficients were from 14.23 to 55.39. Regional infrastructure and telecommunication business strengthened the positive effects of local institutional environment, R\&D input, policies, and research institutions, and the coefficients were from 8.1 to 42.15 and the cross-level relationships were significantly in the first two, but weak in the last one.

At the national level, national industrial policies were not significantly impacting on the innovation activity's spatial distribution in China's NEV industry. Meanwhile, time was also not a significant factor.

\subsubsection{Individual Innovation}

Table 5 is the multilevel analysis results of individual innovation. In innovation activities, individual innovation was more than $82 \%$. Therefore, the multilevel analysis results of individual innovation were highly similar with the results of innovation activities. In the model of individual innovation, the impact of every variable was very similar with the result in the innovation activities model. What is obviously different from innovation activities is that, in individual innovation, those relationships were much stronger. Therefore, the specific influence progress would not be discussed in this subsection. 
Table 5. The multilevel analysis results of individual innovation.

\begin{tabular}{cccccccccc}
\hline & Municipal & InB & InE & R\&D & Fin & HR & Infra & Tele & LP \\
\hline Regional & Coefficient & 2.56 & $39.05^{* * *}$ & $21.57^{* * *}$ & $23.72^{* * *}$ & $41.25^{* * *}$ & 6.55 & -3.90 & $7.87^{* * *}$ \\
\hline InB & $-9.29^{*}$ & - & 15.14 & $17.82^{*}$ & 16.23 & 3.57 & - & - \\
InE & $36.66^{* * *}$ & - & $44.97^{* * *}$ & $48.66^{* * *}$ & $83.87^{* * *}$ & $59.33^{* * *}$ & - & - & $6.89^{*}$ \\
R\&D & $-4.62^{*}$ & - & $21.54^{* * *}$ & $41.88^{* * *}$ & $69.13^{* * *}$ & $40.25^{* * *}$ & - & - & -0.18 \\
Fin & $-2.97^{* *}$ & - & -7.98 & $22.97^{* * *}$ & $31.87^{* *}$ & $30.47^{* * *}$ & - & - & -1.07 \\
HR & $-10.29^{* *}$ & - & 14.74 & $49.56^{* * *}$ & $65.09^{* * *}$ & $52.12^{* * *}$ & - & - & -4.30 \\
Infra & -0.63 & - & $63.83^{* * *}$ & $36.25^{* * *}$ & -13.54 & $37.17^{*}$ & - & - & $15.24^{* * *}$ \\
Tele & $-7.21^{* *}$ & - & $40.95^{* * *}$ & $48.72^{* * *}$ & 5.70 & $33.35^{*}$ & - & - & $12.27^{* *}$ \\
\hline National & - & - & - & - & - & - & - & - \\
\hline P & -2.48 & - & - & - & - & - & - & - \\
T & 0.12 & - & - & - & - & - & - & - \\
\hline
\end{tabular}

Note: ${ }^{*}$ means $p \leq 0.05,{ }^{* *}$ means $p \leq 0.01$, and ${ }^{* * *}$ means $p \leq 0.001$.

\subsubsection{Innovation Networks}

Table 6 is the multilevel analysis result of collaborative innovation. At the municipal level, human resources was still the key factor in local collaborative innovation and its coefficient was 21.86. It reflected laterally whether there are local creation institutions that are important to collaborative innovation. On the other hand, $R \& D$ input and finance capital were critical in collaborative innovation and the coefficients were 12.18 and 5.37 respectively. This means that the locals with higher capital had more advantages in collaboration in China's NEV industry. Besides, the institutional environments' influence was weakly and significantly positive and its effect was only 8.36 . To be noticed, municipal and provincial policies cannot boost collaborative innovation.

Table 6. The multilevel analysis results of collaborative innovation.

\begin{tabular}{cccccccccc}
\hline & Municipal & InB & InE & R\&D & Fin & HR & Infra & Tele & LP \\
\hline Regional & Coefficient & 3.51 & $8.36^{*}$ & $12.18^{* * *}$ & $5.37^{* * *}$ & $21.86^{* * *}$ & 0.53 & 4.27 & -0.18 \\
\hline InB & -3.60 & - & 2.68 & 4.62 & $-24.33^{* * *}$ & 1.07 & - & - \\
InE & $13.28^{* *}$ & - & 7.24 & $14.84^{* * *}$ & -2.89 & $25.80^{* * *}$ & - & - \\
R\&D & $-3.09^{* *}$ & - & -1.15 & $12.03^{* *}$ & $14.16^{* * *}$ & $13.48^{* *}$ & - & - & - \\
Fin & 0.84 & - & 4.11 & $20.75^{* * *}$ & 9.88 & $17.26^{* * *}$ & - & - & - \\
HR & -3.76 & - & 1.67 & $24.73^{* * *}$ & $14.04^{* * *}$ & $17.02^{* *}$ & - & - & - \\
Infra & -4.73 & - & 6.63 & 5.26 & $-43.85^{* * *}$ & 6.65 & - & - & - \\
Tel & 0.21 & - & $16.41^{*}$ & $16.67^{* * *}$ & -12.18 & $17.26^{*}$ & - & - \\
\hline National & - & - & - & - & - & - & - & - \\
\hline P & -0.42 & - & - & - & - & - & - & - \\
T & -0.06 & - & - & - & - & - & - & - \\
\hline
\end{tabular}

Note: ${ }^{*}$ means $p \leq 0.05,{ }^{* *}$ means $p \leq 0.01$, and ${ }^{* * *}$ means $p \leq 0.001$.

At the regional level, the impact of institutional environment could be significantly positive and its coefficient was 13.28. In another words, locals that are in good institutional environment regions could produce NEV industrial collaborative innovation easier. Besides, the relationship between regional $R \& D$ input and local innovation collaboration was significantly negative and the effect was -3.09 . This means that the locals with intense R\&D input do not show great advantages in collaborative innovation output.

In the cross-level relationship from region to local, the regional industrial base and facilities did not strengthen the positive impacts of local finance capital to local innovation. It means that the regions with a good industrial base and facilities cannot certainly boost collaborative innovation. At the same time, the regional R\&D input and human resources were significantly positive to the local R\&D input and human resources and the coefficients 
were from 12.03 to 24.73 . The regional telecommunication business strengthened the positive effect of the local R\&D input and the coefficient was 16.67, but it was relatively weak on the local institutional environment and human resources.

At the national level, national industrial policies were not significantly on the distribution of collaborative innovation. At the same time, time was not a significant factor too.

\section{Discussion and Policy Implications}

\subsection{Discussion}

\subsubsection{Multilevel Mechanism in Innovation Activities}

Specifically, innovation resources and the institutional environment are the two key factors that make innovation activities spatially different. Excellent research institutions can create knowledge at the local level, and they can also continuously provide advanced talent. Since the NEV industry is an emerging high-tech industry, its industrial base is not as important as traditional industry needs. Traditional auto manufacturers' reactions in relation to NEV products are too slow. At the same time, start-ups are getting into the field and starting to dominate the industry. Companies such as Tesla from Silicon Valley in the United States, LG Chem from South Korea, CATL, and BYD from China are typical examples. The supply chain is also being disrupted by those firms in other fields. When we observe those cities that have a better institutional environment, it is obvious that they can cultivate more start-ups. These firms dominate industry innovation. Naturally, those cities that have excellent research institutions and start-ups are hotspots for R\&D inputs and VC investments.

Regions that have large financial investments may not increase local innovation activities. However, cities can benefit from regions with excellent institutional environments. This can be easily understood because innovation inputs between different cities in the region are not the same. Cities which are more powerful have more resource allocation rights. This makes R\&D input territorially different in area, and it also means that innovation activities in small-medium sized cities are under the restrain of megacities. On the other hand, institutional environments are similar in various regions, and most cities can benefit from an excellent institutional environment. Meanwhile, without any exceptions, regional innovation environments enhance the innovation capability of those cities that have excellent resources, especially those that have more talent and financial investment. Against the background of the free institutional environment, innovators agglomerate in those cities, and local innovation output increases consequently. In other words, there is a Matthew effect in the innovation activities' multilevel mechanism.

From the perspective of nationwide, industrial policies are not significant to innovation activities distribution. Based on the results, even if we broaden the limit of significance, the impact of national industrial policies would be negative, and it also means that macro industrial policies are structurally different among areas. Continuously increasing input did not make cities get bonuses. In fact, affected by decentralization, some regions benefit from marketization and globalization, as new financial capital and labor capital appeared in those cities. What is more, motivated by GDP competition among peers, governors who get authorization from higher government tend to publish preferable policies to promote local innovation. Consequently, when a united policy is implemented, the benefit shows a heterogeneous spatial feature. Figure 2 is the multilevel mechanism of innovation activities distribution in China's NEV industry. 


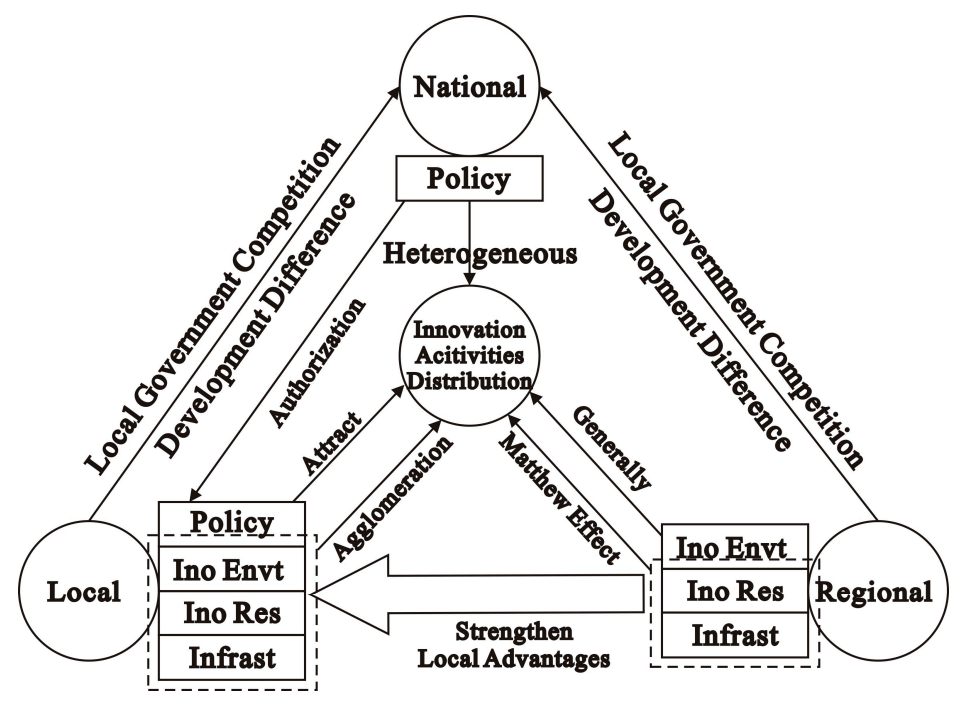

Figure 2. The multilevel mechanism of innovation activities distribution in China's NEV industry.

\subsubsection{Multilevel Mechanism in Collaborative Innovation}

Compared with total innovation activities and individual innovation, the multilevel mechanism of collaborative innovation shows some different features: 1 . Collaborative innovations rely more on local knowledge. In previous studies, some researchers argue that knowledge in the NEV industry has the characteristics of both doing-using-innovation (DUI) and scientific-knowledge-innovation (SKI) [59]. Therefore, from the point of view of knowledge type, tacit knowledge is still important in China's NEV industry innovation. Regions that have the ability to create knowledge are optimum locations for innovators. With innovators agglomerating in space, the externality of local knowledge would increase, and networks among actors are intensified in the process [60]. The geographical proximity feature is significant in these cooperative relationships, and knowledge communication is decreasing with the distance increasing. 2. Collaborative innovations do not rely on industrial policies. The reason of this is that complementary knowledge is the motivation of cooperation among innovators. Comparatively, industrial policies would cause greater opportunism, and this would be more obvious in individual innovation. Therefore, the different innovation motivation finally makes policies from municipal and provincial governments that cannot put great intervention impact on collaborative innovations. 3. The accumulation of capital and technology is the base of collaborative innovation. The collaborations among actors are built by complementary knowledge and this makes collaborative innovation rely more on resource input and not the traditional industrial base and infrastructure. Consequently, actors cluster in places with abundant resources and the agglomerations provide more possibilities for local innovation. Figure 3 is the multilevel mechanism of innovation networks distribution in China's NEV industry. 


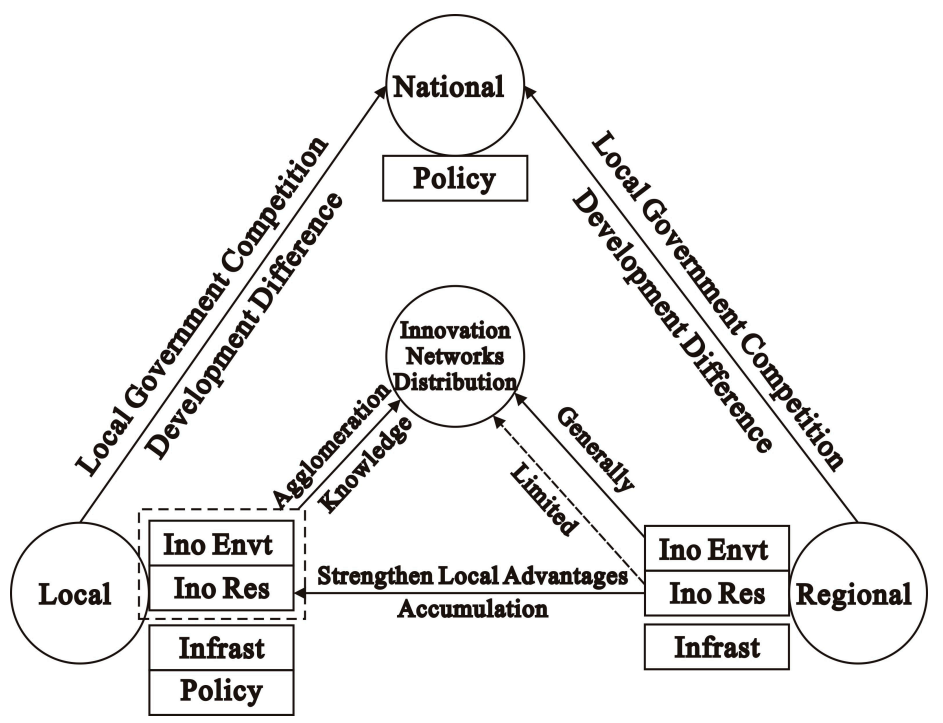

Figure 3. The multilevel mechanism of innovation networks distribution in China's NEV industry.

\subsection{Policy Implications}

From a long-term view, China government will finally quit the subsidy policies in the NEV industry. Currently, the NEV market is in an intensively competitive situation and actors in the industry are facing a great challenge of market restriction. At the same time, industrial subsidy policies are always with opportunism. Based on our research, authors propose that, for local or regional governments, generally, knowledge and facilities are the most important. To improve innovation capacity, the regional policies plan should be based on knowledge institutions. With long term R\&D input, locals can get technological advantages from research institutions. In an open, vital, and protective institutional context, industrial innovation would be active and collaboration would be built naturally.

From a multilevel view, although the national policies could not have a significant effect on NEV innovation distribution, it still plays a role on leading industry development. Therefore, the central government should pay more attention on NEV technological and safety standards to regulate the NEV industry and guide the innovation to a degree. At the regional level, different provincial governments should take more effort in improving institutional environment in locals of the region. Additionally, if the regional policies are more focused on those cities with advantages on the innovation system, the NEV innovation efficiency would be increased too. At the local level, the most important issue is to develop the local knowledge source. Meanwhile, those cities with a good industrial base and knowledge sources should try to attract external financial capital so that innovation and collaboration could be created to a degree.

\section{Conclusions}

In relation to our limited knowledge, we still do not understand the multilevel mechanism of innovation activities, especially the cross-level effect process. On the other hand, studies about the NEV industry mainly focused on the effect of policies on the industry. Therefore, we proposed three questions, "what are the multilevel geographical results caused by central government intervention?", "how do regional and local innovation environment impact innovation activities distribution?", and "how the cross-level effect in multilevel innovation environments works?". We chose China's NEV industry as our research objective and divided innovation activity into individual innovation and collaborative innovation. By collecting China's NEV patents data from SIPO database, we mapped its innovation distribution and analyzed its multilevel mechanism from 2009 to 2014 with ArcGIS and HLM.

The conclusions are as follows. (1) China's NEV industrial innovation activities were clustered at the multilevel and the distributions of individual innovation and collaborative 
innovation were not similar. At the regional level, the BTH, YRD, and PRD were the most agglomerated. At the municipal level, innovation activities in Beijing, Shenzhen, and Shanghai were predominant in the nation. There was a significant difference between innovation activities and innovation networks, as PRD shows an obvious shortage of collaborative innovation. (2) The multilevel mechanism of innovation activities in China's NEV industry is complex. The local innovation resources and institutional environments were critical, those regions with more advantages in resources and institutional environments had more possibilities to create new technology. Different from traditional knowledge, the authors found that not every place benefits from regional innovation resources and facilities. Influenced by decentralization, national policies also could not affect every area in a homogeneous way and its impact on distribution was not significant. (3) The multilevel mechanism of collaborative innovation in China's NEV industry shows some different features. It mainly shows that the knowledge in the NEV industry is of DUI to a degree and this makes collaborative innovation rely on local knowledge, and policies are difficult to intervene the progress. This also makes areas with resources advantages become more competitive too.

There were some limitations in this paper. First, we did not compare the multilevel mechanism in China's NEV innovation during different periods, as there was a time lag between innovation input and innovation output. Second, about the innovation networks, in our study, we located innovation collaboration by its location attribute. In fact, as the applicators were more than one, only using the location attribute in patent data was not integrated.

Some aspects could be concerned by researchers in the future. First, we only analyzed China's NEV innovation from 2009 to 2014 when the subsidy was increasing because of the data availability, so the knowledge about the multilevel mechanism when financial subsidies decline could be studied in future work. Second, as innovation networks could not be highly influenced by policies, it proves that actors' motivation should be given more attention by academicians. Thus, we should analyze the multilevel mechanism of innovation networks from a view of innovators and multidimensional proximities is an important theory in it.

Author Contributions: Writing-Original draft, Kaihuang Zhang; Conceptualization, writingreview and editing, funding acquisition, Kaihuang Zhang and Qinglan Qian; methodology, software, Zhixin Feng; formal analysis, Kaihuang Zhang and Zhixin Feng; supervision, Qinglan Qian. All authors have read and agreed to the published version of the manuscript.

Funding: This article is funded by NATIONAL NATURAL SCIENCE FOUDATION OF CHINA, the number is 41771127 and funded by GUANGDONG CLIMBING PLAN PROJECT, the number is pdjh2020b0472.

Institutional Review Board Statement: Not applicable.

Informed Consent Statement: Not applicable.

Data Availability Statement: The patents data can be found at SIPO, industrial policies are collected from Annual Report on the Development of China Automotive Industry and governments' websites, most of the social-economic data come from the China City Statistical Yearbook, other data are supplemented by China Securities Regulatory Commission, National Science Foundation of China, PEDATA and Web of Science (accessed on 3 June 2021).

Conflicts of Interest: The authors declare no conflict of interest. 


$\begin{array}{ll}\text { Abbreviations } & \\ \text { Abbreviations } & \text { Explanations } \\ \text { NEV } & \text { New Energy Vehicle } \\ \text { PCT } & \text { Patent Cooperation Treaty } \\ \text { CA } & \text { California } \\ \text { NY } & \text { New York } \\ \text { NIS } & \text { National Innovation System } \\ \text { RIS } & \text { Regional Innovation System } \\ \text { NRDC } & \text { National Development and Innovation Committee of China } \\ \text { CNPCD } & \text { Chinese Patent Citation Database } \\ \text { SIPO } & \text { China's State Intellectual Property Office } \\ \text { BTH } & \text { Beijing-Tianjin-Hebei Region } \\ \text { YRD } & \text { Yangtze Delta River Region } \\ \text { PRD } & \text { Pearl Delta River Region } \\ \text { CPR } & \text { Central Plains Region } \\ \text { CCCR } & \text { Chengdu-Chongqing Region } \\ \text { HLM } & \text { hierarchical linear model } \\ \text { VC } & \text { Venture Capital } \\ \text { PE } & \text { Private Equity } \\ \text { LG Chem } & \text { LG Chem Ltd } \\ \text { CATL } & \text { Contemporary Amperex Technology Co., Limited } \\ \text { BYD } & \text { BYD Company Limited } \\ \text { DUI } & \text { Doing-Using-Innovation } \\ \text { SKI } & \text { Scientific-Knowledge-Innovation } \\ \end{array}$

\section{References}

1. WIPO. World Intellectual Property Report 2019: The Geography of Innovation: Local Hotspots, Global Networks; World Intellectual Property Organization: Geneva, Switzerland, 2019.

2. $\quad$ Buzard, K.; Carlino, G.A.; Hunt, R.M.; Carr, J.K.; Smith, T.E. Localized knowledge spillovers: Evidence from the spatial clustering of R\&D labs and patent citations. Reg. Sci. Urban Econ. 2020, 81, 103490.

3. Halbert, L. Collaborative and Collective: Reflexive Co-ordination and the Dynamics of Open Innovation in the Digital Industry Clusters of the Paris Region. Urban Stud. 2012, 49, 2357-2376. [CrossRef]

4. Balland, P.; Boschma, R.; Frenken, K. Proximity and Innovation: From Statics to Dynamics. Reg. Stud. 2015, 49, 907-920. [CrossRef]

5. Figueiredo, O.; Guimaraes, P.; Woodward, D. Industry localization, distance decay, and knowledge spillovers: Following the patent paper trail. J. Urban Econ. 2015, 89, 21-31. [CrossRef]

6. Tödtling, F.; Trippl, M. Regional innovation policies for new path development-beyond neo-liberal and traditional systemic views. Eur. Plan Stud. 2018, 26, 1779-1795. [CrossRef]

7. Lin, L.; Wang, F. Geographical proximity vs network tie: Innovation of equipment manufacturing firms in Shanghai, China. Erdkunde 2019, 73, 185-198. [CrossRef]

8. $\mathrm{Fu}, \mathrm{W}$.; Yang, J. Critical reflections on the geography of innovation: A prospect of theoretical progress from Chinese (in Chinese). Geogr. Res.-Aust. 2020, 39, 1018-1027.

9. Cao, X.; Zeng, G.; Teng, T.; Si, Y. The best spatial scale of firm innovation networks: Evidence from Shanghai high-tech firms. Growth Chang. 2018, 49, 696-711. [CrossRef]

10. Okamuro, H.; Nishimura, J.; Kitagawa, F. Multilevel policy governance and territorial adaptability: Evidence from Japanese SME innovation programmes. Reg. Stud. 2018, 53, 803-814. [CrossRef]

11. Zhou, Z.; Chen, Z.; Li, Y. The adoption behavior of new energy automotive technology in Chinese firms: A knowledge rigidity perspective. J. Renew. Sustain. Energy 2012, 4, 31802. [CrossRef]

12. Yuan, X.; Liu, X.; Zuo, J. The development of new energy vehicles for a sustainable future: A review. Renew. Sustain. Energy Rev. 2015, 42, 298-305. [CrossRef]

13. Carlino, G.; Kerr, W.R. Chapter 6-Agglomeration and Innovation. In Handbook of Regional and Urban Economics; Duranton, G., Henderson, J.V., Strange, W.C., Eds.; Elsevier: Amsterdam, The Netherlands, 2015; Volume 5, pp. 349-404.

14. Porter, M.E. Clusters and the New Economics of Competition. Harv. Bus. Rev. 1998, 76, 77-90. [PubMed]

15. Delgado, M.; Porter, M.E.; Stern, S. Clusters and entrepreneurship. J. Econ. Geogr. 2010, 10, 495-518. [CrossRef]

16. Jimenéz, K.P.; Junquera, B. Why are clusters beneficial? A review of the literature. Hum. Factors Ergon. Manuf. 2010, 20, 161-173. [CrossRef]

17. Unger, J.M.; Rauch, A.; Frese, M.; Rosenbusch, N. Human capital and entrepreneurial success: A meta-analytical review. J. Bus. Ventur. 2011, 26, 341-358. [CrossRef] 
18. Acs, Z.J.; Audretsch, D.B.; Lehmann, E.E. The knowledge spillover theory of entrepreneurship. Small Bus. Econ. 2013, 41, 757-774. [CrossRef]

19. Bathelt, H.; Malmberg, A.; Maskell, P. Clusters and knowledge: Local buzz, global pipelines and the process of knowledge creation. Prog. Hum. Geogr. 2004, 28, 31-56. [CrossRef]

20. Boschma, R. Proximity and Innovation: A Critical Assessment. Reg. Stud. 2005, 39, 61-74. [CrossRef]

21. Escribano, A.; Fosfuri, A.; Tribó, J.A. Managing external knowledge flows: The moderating role of absorptive capacity. Res. Policy 2009, 38, 96-105. [CrossRef]

22. Rost, K. The strength of strong ties in the creation of innovation. Res. Policy 2011, 40, 588-604. [CrossRef]

23. Teresa Bolivar-Ramos, M. New ventures' collaborative linkages and innovation performance: Exploring the role of distance. J. Manag. Organ. 2019, 25, 26-41. [CrossRef]

24. Gertler, M.S. Tacit knowledge and the economic geography of context, or the undefinable tacitness of being (there). J. Econ. Geogr. 2003, 3, 75-99. [CrossRef]

25. Schot, J.; Steinmueller, W.E. Three frames for innovation policy: R\&D, systems of innovation and transformative change. Res. Policy 2018, 47, 1554-1567.

26. Fitjar, R.D.; Huber, F. Global pipelines for innovation: Insights from the case of Norway. J. Econ. Geogr. 2014, 15, 561-583. [CrossRef]

27. Casadella, V.; Uzunidis, D. National Innovation Systems of the South, Innovation and Economic Development Policies: A Multidimensional Approach. J. Innov. Econ. 2017, 23, 137-157. [CrossRef]

28. Sun, X.; Liu, X.; Wang, Y.; Yuan, F. The effects of public subsidies on emerging industry: An agent-based model of the electric vehicle industry. Technol. Forecast. Soc. Chang. 2019, 140, 281-295. [CrossRef]

29. Pohl, H.; Yarime, M. Integrating innovation system and management concepts: The development of electric and hybrid electric vehicles in Japan. Technol. Forecast. Soc. Chang. 2012, 79, 1431-1446. [CrossRef]

30. Kim, E.S.; Bae, K.J.; Byun, J. The History and Evolution: A Big Data Analysis of the National Innovation Systems in South Korea. Sustainability 2020, 12, 1266. [CrossRef]

31. Lundvall, B. National Systems of Innovation: Towards a Theory of Innovation and Interactive Learning; Pinter: London, UK, 1992.

32. Speldekamp, D.; Knoben, J.; Saka-Helmhout, A. Clusters and firm-level innovation: A configurational analysis of agglomeration, network and institutional advantages in European aerospace. Res. Policy 2020, 49, 103921. [CrossRef]

33. He, J.; Huang, X.; Si, Y. Local embeddedness and global production network of industrial clusters: Case study of the cultural creative districts in Shanghai (in chinese). Geogr. Res.-Aust. 2018, 7, 1447-1459.

34. Zhu, S.; Huang, Y.; Hu, X. Research framework and prospect of industrial value chain upgrading and spatial upgrading based on a multiple scale perspective (in chinese). Prog. Geogr. 2020, 39, 1367-1384. [CrossRef]

35. Zhu, S.; He, C.; Luo, Q. Good neighbors, bad neighbors: Local knowledge spillovers, regional institutions and firm performance in China. Small Bus. Econ. 2019, 52, 617-632. [CrossRef]

36. He, C.; Wei, Y.D.; Xie, X. Globalization, Institutional Change, and Industrial Location: Economic Transition and Industrial Concentration in China. Reg. Stud. 2008, 42, 923-945. [CrossRef]

37. Pan, F.; He, C. Regional difference in social capital and its impact on regional economic growth in China. Chin. Geogr. Sci. 2010, 20, 442-449. [CrossRef]

38. Boschma, R.; Capone, G. Institutions and diversification: Related versus unrelated diversification in a varieties of capitalism framework. Res. Policy 2015, 44, 1902-1914. [CrossRef]

39. Martin, R.; Sunley, P. Path dependence and regional economic evolution. J. Econ. Geogr. 2006, 6, 395-437. [CrossRef]

40. Teng, T.; Zhang, Y.; Si, Y.; Chen, J.; Cao, X. Government support and firm innovation performance in Chinese science and technology parks: The perspective of firm and sub-park heterogeneity. Growth Chang. 2020, 51, 749-770. [CrossRef]

41. Seyoum, B. Modularity in Production and Firm Relative Positional Advantage: Evidence from the Global Automobile Industry in China. J. East-West Bus. 2021, 1-28. [CrossRef]

42. Chen, H.; Gompers, P.; Kovner, A.; Lerner, J. Buy local? The geography of venture capital. J. Urban Econ. 2010, 67, 90-102. [CrossRef]

43. Alvarado-Vargas, M.J.; Callaway, S.K.; Ariss, S. Explaining innovation outputs by different types of R\&D inputs: Evidence from US universities. J. Strat. Manag. 2017, 10, 326-341.

44. Seddighi, H.R.; Huntley, P.J. R\&D Activities in a Peripheral Region: An Empirical Study with Special Reference to the North East Region of the UK. Econ. Innov. New Technol. 2007, 16, 211-225.

45. Hansen, H.K.; Winther, L. The spatial division of talent in city regions: Location dynamics of business services in Copenhagen. Tijdschr. Voor Econ. Soc. Geogr. 2010, 101, 55-72. [CrossRef]

46. Donegan, M.; Lowe, N. Inequality in the Creative City: Is There Still a Place for "Old-Fashioned" Institutions? Econ. Dev. Q. 2008, 22, 46-62. [CrossRef]

47. Wang, S.; Fan, J.; Zhao, D.; Wang, S. Regional innovation environment and innovation efficiency: The Chinese case. Technol. Anal. Strateg. Manag. 2016, 28, 396-410. [CrossRef]

48. Zhou, T.; Zhao, H.; Liu, Z. Annual Report of China's City Innovation (2019) (in Chinese); Social Sciences Academic Press (China): Beijing, China, 2019.

49. Kimble, C.; Wang, H. China's new energy vehicles: Value and innovation. J. Bus. Strategy 2013, 34, 13-20. [CrossRef] 
50. Gong, H.; Wang, M.Q.; Wang, H. New energy vehicles in China: Policies, demonstration, and progress. Mitig. Adapt. Strategy Glob. Chang. 2013, 18, 207-228. [CrossRef]

51. Liu, Y.; Kokko, A. Who does what in China's new energy vehicle industry? Energy Policy 2013, 57, 21-29. [CrossRef]

52. Zhang, X.; Bai, X. Incentive policies from 2006 to 2016 and new energy vehicle adoption in 2010-2020 in China. Renew. Sustain. Energy Rev. 2017, 70, 24-43. [CrossRef]

53. Figenbaum, E. Perspectives on Norway's supercharged electric vehicle policy. Environ. Innov. Soc. Transit. 2017, 25, 14-34. [CrossRef]

54. Zhang, X.; Rao, R.; Xie, J.; Liang, Y. The Current Dilemma and Future Path of China's Electric Vehicles. Sustainability 2014, 6, 1567-1593. [CrossRef]

55. Wang, D.; Zhao, X.; Zhang, Z. The Time Lags Effects of Innovation Input on Output in National Innovation Systems: The Case of China. Discret. Dyn. Nat. Soc. 2016, 2016, 1-12. [CrossRef]

56. Sun, H.; Geng, Y.; Hu, L.; Shi, L.; Xu, T. Measuring China's new energy vehicle patents: A social network analysis approach. Energy 2018, 153, 685-693. [CrossRef]

57. Ma, Y.; Shi, T.; Zhang, W.; Hao, Y.; Huang, J.; Lin, Y. Comprehensive policy evaluation of NEV development in China, Japan, the United States, and Germany based on the AHP-EW model. J. Clean. Prod. 2019, 214, 389-402. [CrossRef]

58. Li, Y.; Wei, Y.H.D. A Spatial-Temporal Analysis of Health Care and Mortality Inequalities in China. Eurasian Geogr. Econ. 2010, 51, 767-787. [CrossRef]

59. Binz, C.; Truffer, B. Global Innovation Systems-A conceptual framework for innovation dynamics in transnational contexts. Res. Policy 2017, 46, 1284-1298. [CrossRef]

60. Cao, X.; Zeng, G.; Ye, L. The structure and proximity mechanism of formal innovation networks: Evidence from Shanghai high-tech ITISAs. Growth Chang. 2019, 50, 569-586. [CrossRef] 